\title{
A LOUCA E O PROFETA: DIFERENTES EFEITOS DE SENTIDOSPARA A "PALAVRA DIVINA"
}

\section{Giselle de Castro de Carvalho'}

Resumo: Uma esquizofrênica internada pela morte do filho e um profeta assimilado pelo imaginário de uma cidade como Rio de Janeiro, é possível traçar alguma relação discursiva entre seus textos? As formações lingüístico-discursivas que constituem alguns dos imaginários religiosos da sociedade contemporânea podem marcar diferenças entre textos delirantes e textos assimilados como "profecia"? Existem diferenças qualitativas na reprodução de formações discursivas de R.S. e na "pregação da palavra divina" do Profeta Gentileza? Ou é o efeito de sentidos causado por seus discursos que faz a diferença?

Palavras-Chave: discurso, sentido, efeito de sentidos, loucura.

\section{Introdução}

José Datrino (1917-1996), o Profeta Gentileza, era um empresário, dono de uma transportadora de cargas no Rio de Janeiro, que se abalou profundamente ao saber do incêndio de um circo, em Niterói, em 17 de dezembro de 1961. Após seis dias desse fato, ele afirma ter recebido um chamado divino para que deixasse tudo que tinha para assumir uma missão e uma nova identidade, Jozzé Agradecido, ou ainda Gentileza.

O assim autonomeado Profeta Gentileza pregava as palavras de Jesus Cristo principalmente pelas ruas do Rio de Janeiro, pintando murais sobre pilastras e viadutos entre o Cemitério do Caju e a Rodoviária Novo Rio. Foram trinta e cinco anos de vida "profética" que se inscreveram no imaginário da cultura brasileira, transformando-o em um verdadeiro Profeta. A cidade do Rio de Janeiro e algumas outras cidades brasileiras, por onde peregrinou, se acostumaram a ver aquele senhor vestido com roupas de profeta (uma bata branca) carregando estandartes com seus escritos ou pintando pilastras.

1 Mestre em Letras; Universidade Federal Fluminense, Niterói, R.J. 
O título de Profeta foi criado por ele mesmo no final da década de sessenta quando esteve em Mirandópolis, interior de São Paulo, cidade próxima de onde nasceu, Cafelândia. Gentileza foi internado três vezes como "maluco" mas acabou por deixar o manicômio com o aval do médico, o qual afirmara que ele era apenas um "pregador" (cf. GUELMAN, 2000).

R. S., nascida em 1948, paciente diagnosticada como esquizofrênica ${ }^{2}$ e internada em um hospital psiquiátrico da Argentina em 25 de outubro de 1979, casada, trinta e um anos, mata o próprio filho de três anos, afirmando ter ouvido vozes alertando-lhe que o menino era o demônio. Por esse motivo, encontrava-se, na época da gravação, em uma cela de isolamento na Alcadía de Comodoro Rivadavia, Província de Chubut. A Dra. A., médica psiquiátrica do Hospital Regional dessa cidade diagnosticou o caso como uma esquizofrenia, apesar de R.S. não se declarar insana.

Gentileza e R. S. afirmam possuir dons divinos, colocam-se como divulgadores da palavra divina e têm missōes a cumprir; ele diz ter a atribuição de:

[01] vir como São José, representar Jesus de Nazaré na Terra, perdoar toda a humanidade, ensinar a perdoar uns aos outros... ;

ela diz ter vindo como o Cristo em corpo de mulher para salvar o mundo inteiro mas também veio como o próprio Deus para vencer o demônio:

[02] Ninguém pode vencer o demônio senão é o mesmo Deus que o está vencendo.

2 O DSM-IV (Diagnostic and Statistical Manual of Mental Disorders, $4^{\text {th }}$ ed.), manual para o diagnóstico das doenças mentais descreve como critérios diagnósticos para a Esquizofrenia: delírios (bizarrias), alucinações (vozes que comentam o comportamento ou os pensamentos da pessoa ou vozes conversando entre si); discurso desorganizado (freqüente descarrilamento ou incoerência); comportamento amplamente desorganizado ou catatônico; sintomas negativos (embotamento afetivo); disfunçāo social/ocupacional (cf. KAPLAN, 1997, p.452). 
Apesar de ambos seguirem o que chamam de missão divina, o que R.S. diz não se inscreve no imaginário da fé cristã, diferentemente do que acontece com o Profeta. Por princípio, quem faz profecias está inserido em uma instância de fé que legitima a verdade cristã. A fé religiosa e as interpretaçōes atribuídas a ela se encaixam em um sistema de crenças compartilhadas e, dentro desse sistema, é legítima a crença em profecias (cf. NOVAES, 2002). No caso da esquizofrenia, apesar de haver uma certeza inabalável que legitima a verdade de um sujeito, essa verdade não faz efeito de sentido e não pode ser compartilhada.

O interesse pela presença do discurso religioso cristão na fala de uma esquizofrênica está no fato de que ela se apropria de formações lingüísticas presentes na Bíblia de tal forma que "assume" o próprio lugar de Deus e, por vezes, o lugar de Cristo. Isso causa um estranhamento, pois, apesar de usar um discurso de devoção cristã, sua fala é praticamente ininteligível:

[03] Eu sou a crista que vocês não crucificaram.

No caso do Profeta, ele utilizava o discurso de devoção e reproduzia formações lingüísticas que não eram consideradas transgressão aos preceitos cristãos e seus textos foram assimilados, social e culturalmente, no imaginário dos brasileiros:

[04] Quando nós somos bons e obedecemos a Deus, então nós somos lâmpada iluminada.

São duas falas baseadas no discurso religioso cristão de devoção. Entretanto, a fala de R.S. poderia ser considerada uma transgressão, pois é ilegítimo ser Deus; enquanto a do Profeta é socialmente aceita. Os profetas são milenariamente conhecidos ${ }^{3}$, sendo assim suas falas poderiam se-utilizar do recurso da ultrapassagem, já que eles teriam alcançado o dom da profecia concedido por Deus.

3 Cf. Bíblia Sagrada, Antigo Testamento, 1980. 


\section{Ultrapassagem e transgressão}

Ultrapassagem e transgressão são duas regras implícitas do conceito de reversibilidade. A noção de reversibilidade define o espaço de discursividade, já que os papéis de locutor e ouvinte não são fixos: "um se define pelo outro" (ORLANDI, 1987, p.239). Nessa dinâmica, traduz-se a própria condição do discurso, o que possibilita a troca de papéis, daí o termo reversibilidade. Não é uma troca absoluta, um não assume totalmente o papel do outro, e, por vezes, não é possível, como nos discursos que tendem a ter regras mais rígidas para os lugares de enunciação, como é o caso do discurso religioso.

Se, na maioria das formas de discurso, existe a noção de reversibilidade, no discurso religioso existe, na verdade, uma "ilusão da reversibilidade" visto que, se essa noção desaparecesse totalmente, o discurso não existiria, romper-se-ia. Por isso, deve-se mantê-lo aparentemente reversível e essa ilusão se mantém de várias formas (cf. ORLANDI, op. cit.).

Uma das formas de ilusão é a profecia. Quando o profeta alcança um dom divino, isso é considerado uma ultrapassagem. Já a fala do louco, que se diz Deus, é considerada uma transgressão, pois ele reverte totalmente a relação de interlocução, ao ocupar um lugar impossível de ser ocupado.

A ilusão da reversibilidade cria o sentimento de identidade com Deus através de mecanismos próprios, quais sejam, as formas legítimas de ultrapassagem. O outro mecanismo, a transgressão, caracteriza a forma ilegítima dos mecanismos impróprios. Essa seria uma forma de experimentar o lugar do poder absoluto divino e representa "uma quebra das regras do jogo" ou "a usurpação do lugar de Deus" (ibid., p.254). A transgressão é uma maneira de tentar ocupar um lugar nunca ocupado antes por alguém visto ser "proibido" igualar-se a Deus.

Em muitos trechos da fala de R.S. observamos a vontade de poder, a transgressão total, ora ela é o Criador, ora ela é o filho Dele, revelando seu espírito de grandeza e poder. Em seu imaginário de 
deusa/crista ela se considera onipotente e transparece a megalomania; i.e., a mania de grandeza, ou a superestima patológica de si mesmo ${ }^{4}$ :

[05] Vocês esperam o Cristo e Cristo não virá. Se crucificaram o Cristo, a esta mulher näo crucificarão. Eu sou a crista que esperam e em corpo de mulher vim(...) por salvar o mundo inteiro(...) A verdade lhes falei, no corpo de Cristo, e a mim por falar a verdade me crucificaram;

Gentileza, ao ocupar um lugar de divulgador das palavras divinas, ganha o status de profeta e autentica a ultrapassagem. R.S., em oposição, não se coloca como divulgadora dessas palavras, mas como o próprio Deus - ou melhor, como "deusa/ crista". Sua fala não é autenticada como profecia, mas como delírio.

Diferentes sentidos para a pregação da "palavra divina"

O Profeta Gentileza não fazia profecias no sentido de previsões. Ele pregava especialmente sobre a "gentileza" e ficou famoso com a frase "gentileza gera gentileza", pintada em vários muros da cidade do Rio de Janeiro.

Para Pêcheux (1997a), uma palavra. uma expressão, uma proposição etc. não têm um sentido que lhes seja próprio, vinculado à sua literalidade. Ao contrário, seu sentido constitui-se em dada formação discursiva nas relações que mantém com outras palavras, expressões, proposições etc., i.e., essas "mudam de sentido segundo as posições sustentadas por aqueles que as empregam" (ibid., p.160, em itálico no original). Assim sendo, uma formação discursiva, ou discurso, é efeito de sentido entre interlocutores.

O "efeito de sentido" causado por uma formação discursiva está diretamente relacionado às condições de produção em que a mesma é proferida. Vale dizer, são as "circunstâncias" de um discurso, seu contexto ou situação, que servem como "pano de fundo específico" para tornar possíveis sua formulação e compreensão (id. 1969, p.75). As condições de produção designam a situação no sentido concreto do termo, i.e., "o ambiente material e constitucional" (id., 1975, p.171).

4 Cf. Dicionário Aurélio Século XXI, 2000. 
Por um lado, as condições de produção do discurso de Gentileza asseguram-lhe o 'título' de profeta: sua própria aparência um senhor de cabelos e barbas longos vestido com uma bata branca; suas palavras de exortação à prática do bem - gentileza, amor etc. - e o lugar bastante visível e de grande circulação de veículos e pessoas onde pintava suas pregações - viadutos, muros, pilastras. Por outro lado, essas mesmas condições de produção o colocariam em uma posição de louco, pois ele largou tudo o que tinha para "pregar as palavras de Jesus e/ou Deus'. Ele teria "surtado", i.e., teria apresentado, mais ou menos repentinamente, sintomas associados às psicoses; teria tido um surto psicótico ${ }^{5}$, a partir do momento em que soube do incêndio do circo.

As formações discursivas definem-se como aquilo que, a partir de uma posição dada em uma conjuntura sócio-histórica, pode e deve ser dito. "Diremos então que toda formação discursiva deriva de condições de produção específicas" (PÊCHEUX, 1975, p.166). Desse modo, diferentes condições de produção podem causar diferentes efeitos de sentido e, se "o sentido sempre pode ser outro (...) nada garante que um discurso produza o mesmo sentido tanto para quem formulou como para que o interpretou" (INDURSKY, 1998, p.12).

Então temos, por um lado, Gentileza dizendo coisas que podem ser ditas - as pregações - e as condições de produção de suas formações discursivas favorecendo sua interpretação como tal. Por outro lado, o discurso de R.S. é proferido a partir de um crime; após matar o filho, passa a "pregar" sua missão de "deusa/crista". Além do mais, diz coisas que não devem ser ditas:

[06]... Eu sou a crista que esperam e em corpo de mulher vim/ um filho eu perdi/ por salvar o mundo inteiro/ um filho eu matei/ um filho por demônio... .

Mas, mesmo quando diz algo que pode ser dito, visto também utilizar o discurso de pregação para divulgar sua 'missão divina':

[07] ... por salvar o mundo inteiro,

nada lhe é favorável, visto as condições de produção de seu discurso envolverem um assassinato; suas formações discursivas são vistas como delírio. 
"PALAVRA DIVINA"

A periculosidade afeta sobremaneira o discurso de R.S., mas não é só por isso que ela é considerada louca. Em outra hipótese, se ela não tivesse matado seu filho, seu discurso continuaria soando estranho por causa de sua transgressão ao "ocupar" o lugar de Deus.

No caso do Profeta Gentileza, suas "profecias" duraram trinta e cinco anos, pois "anunciavam" a palavra de Deus e refletiam o que as pessoas estavam vivendo naquele dado momento, a falta de gentileza. A atualidade, marcada pela insensibilidade social, coloca a gentileza como "princípio ético" e convoca à memória dos brasileiros um de seus "traços genuínos", a cordialidade, há algum tempo esquecida (cf. GUELMAN, 2000).

As palavras não significam em si, mas, quando uma palavra significa, é "porque ela tem textualidade, ou seja, porque a sua interpretação deriva de um discurso que a sustenta" (ORLANDI, 1996, p.52). A palavra gentileza ganha significação por si ao representar uma pregação que tem a sustentação de um 'discurso do bem'. Ganha ainda mais força no enunciado "gentileza gera gentileza" que a provê de "realidade significativa" (ibidem).

Freud afirma haver uma origem psíquica para o surgimento das idéias religiosas. Assim sendo, a religião supriria a necessidade de um pai poderoso que superaria a sensação de desamparo do sujeito; estabeleceria uma ordem moral mundial; e confortaria os sujeitos, pois prolongaria a vida terrena com a promessa de uma vida futura. Dessa forma, supriria principalmente "a necessidade de o homem tolerar seu desamparo" (FREUD, 1927, p.30) através da influência de indivíduos que possam fornecer um exemplo e a quem o homem reconheça como líderes (ibid., p. 18).

O Profeta Gentileza traz à tona uma simbolização corrente no imaginário cultural brasileiro, que aproxima Jesus e Tiradentes, mártires e heróis, comumente retratados com cabelos e barbas longas (cf Guelman, op.cit.). Ao assumir fisicamente essa imagem, a qual remonta aos profetas bíblicos, acaba assumindo também o lugar de pai protetor:

[08] Se alguém perguntar quem é Gentileza, vocês ensinam: é o nosso Pai, Criador celestial 
Gentileza resgata para si um efeito mítico, pois, ao se autodenominar e se vestir como Profeta, suas palavras causavam impacto à sensibilidade das pessoas. Seu discurso, na maioria das vezes, não era considerado delírio porque não passava pelo julgamento racional delas. Ao contrário, como eram palavras de conforto e de amparo, reforçavam o status de profeta.

Para aqueles que o viam como "profeta" - e ainda o vêem, pois sua obra continua exposta nos muros e pilastras da cidade - ouvir ou ler suas palavras era como ouvir ou ler as palavras de Deus. Afinal de contas, são palavras que invocam a paz, o amor e a gentileza por um mundo melhor.

O alcance e a eficácia da palavra gentileza revela-se porque é "a própria afetividade divina que ultrapassa a condição de uma ética interpessoal" (Guelman, op.cit., p.15) e a ética está relacionada a valores racionais visto se referir a juízos de valor suscetíveis de qualificação do ponto de vista do bem e do $\mathrm{mal}^{6}$. No caso de R.S., como suas palavras causam tamanha estranheza e desconforto, passam por uma análise racional e são qualificadas como "do mal". Não obstante ela utilizar formações discursivas de divulgação da palavra divina, essas não causam efeito de sentido como tal.

\section{A assimetria do discurso religioso}

A relação falante/ouvinte e a forma da representação da voz divina mantêm a distância entre o dito de Deus e o dizer do homem. Essa separação entre significação divina e a linguagem humana deriva da assimetria entre os planos. Tal assimetria estabelece e mantém a obscuridade da significação divina (cf. ORLANDI, 1987).

Dias (1987) afirma que existe assimetria no discurso religioso, haja vista locutor e ouvintes jamais estarem no mesmo plano. Dessa assimetria, virão outras porque a desigualdade imortalidade/mortalidade instala a relação vida/morte, a qual acarreta a necessidade de salvação para a vida eterna. A salvação se dá pela fé em se alcançar a vida eterna. A assimetria no discurso religioso caracteriza a nãoreversibilidade, pois locutor (o Papa e demais sacerdotes) e ouvintes

6 Cf. Dicionário Aurélio Século XXI, 2000 
(os fiéis) não podem trocar seus papéis, os homens não podem jamais ocupar o lugar de Deus.

R.S. subverte a relação de assimetria, característica desse discurso. Ela se coloca em total simetria com Deus/ Cristo, ela é Ele e também é Seu filho; ela está no mesmo plano que eles, ela não os representa, ela é, ela tem poderes. Simetria quer dizer que duas partes situadas em lados opostos se correspondem, são iguais. Enquanto no discurso religioso existe uma total assimetria entre os planos temporal e espiritual, no discurso analisado, existe mais que simetria, pois não existem dois lados, dois planos, a paciente esquizofrênica R.S. é o "plano Deus", o "plano Criador".

Gentileza também se coloca em simetria com Deus e com um dos santos da Igreja Católica:

[09] Eu não sou mais do que ninguém, pela minha missão, que o Pai me deu, eu sou de vocês o irmão mais velho. Eu sou São José. Vou aprovar vocês e o mundo;

porém, essa assunção como "ser divino" não afeta sua imagem de profeta pregador. Suas palavras gravaram-se no imaginário de muitos brasileiros através da mensagem "gentileza gera gentileza", a qual acabou por tornar-se uma "palavra-gesto" estabelecendo uma relação social e uma ética, propagando-se e estendendo-se em várias direções (Guelman, op.cit., p.15).

A transgressão de R.S., antes de ser a de ocupar um lugar "proibido", é a de violar o sexto dos dez mandamentos: "Não matarás" (Êxodo, 20:13) ". Todavia, além de os dez mandamentos fundamentarem os princípios cristãos, alguns deles também são guias para as leis morais e jurídicas em muitas sociedades. Transgredir uma dessas leis cristãs, como a sexta, também é violar uma lei moral e jurídica. R.S. poderia então estar presa em um presídio comum e não internada em um manicômio; contudo ela transgride não só a Lei, mas transgride as leis implícitas do discurso religioso, as quais colocam falante (Deus) e ouvintes (os fiéis) em seus devidos lugares. Desse

7 Os dez mandamentos (ou as dez Leis de Deus) estão no livro Êxodo, um dos cinco livros da Bíblia cristã que compõem o Pentateuco e guiam as religiões judaico-cristãs (cf. NARLOCH, 2003, p.21). 
modo, R.S. tem um grau de periculosidade que "agrava" a transgressão de querer ocupar um lugar proibido, o lugar de Deus.

Gentileza não é considerado um transgressor, apesar de "ocupar" o lugar de São José, nem tem o traço de periculosidade, pelo contrário, é considerado apenas um pregador do bem e, sobretudo, da gentileza. Além do mais, seus atos de fala reproduzem um discurso reconhecido por muitos.

A repetição dos atos de fala

Novaes (1997) observa que, na linguagem dos loucos, no significado locucionário de seus atos de fala, a verdade parece ser uma das principais questões. Daí, concluir que o louco antecipa de certa forma o consentimento do interlocutor na verdade colocada em seus atos de fala visto ignorar que tal verdade cause estranhamento ao outro.

Isso pode ser facilmente reconhecido nos atos de fala de R.S. e no de Gentileza; para ambos, suas missões representam suas verdades e eles agem de acordo com elas: ela mata o filho que seria o demônio para salvar "o mundo inteiro" e ele propaga as palavras de Jesus para "mostrar o caminho da verdade". Ambos agem de acordo com suas verdades e propagam suas 'missões', alheios ao estranhamento causado a quem quer que seja.

Ainda segundo Novaes (1999), se seus atos de fala não cumprem sua eficácia comunicativa, i. e., se não são compreendidos, isso se dá porque o mundo representado por eles não é comum aos interlocutores.

A repetição dos atos de fala constitutivos do imaginário religioso é fator imprescindível da memória discursiva que possibilita os diversos dizeres, sejam na Igreja, nos discursos leigos e nas falas delirantes e de pregação profética. A memória discursiva refere-se ao interdiscurso, lugar onde teríamos todos os dizeres 'já-ditos', referindo-se ao momento da constituição do discurso. Em contrapartida, há o intradiscurso aquilo que estamos dizendo na atualidade, i.e., no momento da formulação do discurso. Na confluência entre inter- e intradiscurso está o dizer (cf. ORLANDI, 2001). Isso quer dizer que para um discurso "fazer sentido", é necessária a ocorrência anterior de outros sentidos já fixados na 
memória discursiva, que possam ser filiados ao acontecimento presente (MARIANI, 1998, p.41).

A forte presença do discurso religioso cristão em vários outros discursos e a reprodução que se faz desse discurso pode ser marcadamente repetitiva, ou "diluída" em vários discursos marcadamente éticos. A fala de R.S. incomoda porque ela "incorpora" essa memória discursiva, que nós reconhecemos no discurso religioso: ela não só reproduz o discurso religioso como o toma para si, ocupando o lugar de autoria desse discurso, colocando-se no lugar de Jesus ou de Deus. Ocupa esses lugares de tal forma que como deusa/crista tirou a vida do filho para salvar a humanidade; ela mesma diz que, como mãe, não faria isso, mas o fez na qualidade de deusa para proteger a humanidade do demônio e livrá-la do pecado. As questões que ela coloca, temor ao demônio, pecado, salvação etc., estão no imaginário dos cristãos. Mas, no imaginário dela, essas questões são de sua responsabilidade.

\section{O jogo de sentidos no discurso da loucura}

Em se falando de obscurantismo no discurso religioso cristão, poder-se-ia pensar em diferentes interpretações do texto sagrado, ou polissemia, o que nunca pode acontecer, pois isso seria considerado uma transgressão. Os sentidos têm de se manter praticamente monossêmicos. A repetição, assim como a interpretação da palavra de Deus, é regulada e é própria da Igreja assim como "o texto próprio é a Bíblia, que é a revelação da palavra de Deus e o lugar próprio para a palavra é determinado segundo as diferentes cerimônias" (ORLANDI, 1987 , p.246, grifos da autora). Tal discurso tenta ao máximo manter seu sentido único e estancar a polissemia.

Entretanto, quando se trata do discurso religioso na loucura, R.S. joga com poli- e monossemia conforme esteja falando do discurso religioso, no primeiro caso, ou de seu próprio delírio, no segundo. No primeiro caso, atribui o sentido que lhe convém ou que está mais de acordo com suas crenças particulares quando fala, por exemplo, da volta do Messias (algo que é fervorosamente acreditado pelos cristãos):

[10] Vocês esperam o Cristo e Cristo não virá (...) Eu sou a crista que esperam e em corpo de mulher eu vim. 
No segundo caso, o sentido fecha-se totalmente, tornando-se monossêmico para ela e completamente sem sentido algum para quem lê o texto:

[11] À víbora há que lhe esmagar a cabeça porque mulher por mulher é a víbora na cabeça;

[12] baixa um OVNI a buscá-lo no espírito de Deus.

O Profeta Gentileza também faz sua interpretação do que seriam as palavras de Jesus e/ou de Deus, transformando seu sentido a seu modo e trazendo a polissemia para seu discurso. Contudo, para ele, suas palavras têm um sentido único e verdadeiro, pois, afinal de contas, ele recebera a "missão" de propagá-las.

Considerações finais

O imaginário religioso apresenta-se com algumas semelhanças na fala da paciente esquizofrênica, pois ela reproduz coisas que os cristãos falam e outras que estão na Bíblia. Os cristãos, no máximo, acreditam nas ultrapassagens legítimas, nos milagres, por exemplo, mas R.S. transgride totalmente, pois é ilegítimo ser Deus. "Como o louco não domina o excesso e foge ao ideal de moderação revela-se aí o desvio que vai distingui-lo dos outros indivíduos" (NOVAES, 1996, p.22). O 'ideal de moderação' no discurso religioso poderia ser representado pela ultrapassagem e o 'desvio', pela transgressão.

As declarações de R.S. causam o estranhamento e o desconforto porque não entendemos o que ela está dizendo, apesar de ela usar corretamente o espanhol falado na Argentina. De acordo com - Manual de diagnóstico de doenças mentais seu discurso é extremamente desorganizado, incoerente, e descarrila com frequiência (cf. KAPLAN, 1997).

No caso de Gentileza, ao usar a repetição de palavras como "gentileza, paz, amor, beleza, natureza" causa um efeito de sentido favorável às pessoas e, mesmo sendo considerado "doido" por muitos, não chega a causar medo ou desconforto. Suas repetições não incomodam nem transgridem; teriam o "ideal de moderação" tolerável.

Fica claro que R.S. está "assujeitada", de uma certa forma, ao imaginário religioso cristão, o qual se constrói, principalmente, sobre as bases da monossemia e da assimetria. Esse sujeito transgride 


\section{"PALAVRA DIVINA"}

radicalmente essas bases, i.e., R.S. interpreta e "abre" os sentidos do discurso religioso como lhe convém. Porém ela também "fecha" totalmente os sentidos de seu discurso colocando coisas - víboras, OVNIS etc. - que só são inteligíveis para ela, construindo um discurso monossêmico e próprio. Além disso, mais do que se colocar em simetria com Deus, ela se coloca em Seu lugar, causando um efeito de sentido negativo.

Gentileza também está fortemente ligado ao discurso religioso cristão e a reprodução que faz do mesmo demonstra que está "assujeitado" a esse discurso. Entretanto, sua repetição deixa-o em uma posição de "profeta do bem" e causa um efeito positivo.

O Profeta então, através de sua frase-tema, anuncia uma alternativa para a crise social, visto o uso de a gentileza gerar gentileza, em sua extensão, por toda parte. Além do mais, "a gentileza, enquanto afetividade e atributo divino, só pode gerar-se, cumprindo o preceito bíblico, no verbo, e assim fazer-se" (GUELMAN, op.cit., p.16).

Referências

BÍBLIA SAGRADA, Edição Ecumênica. Mirador, Encyclopaedia Britannica Publishers, Inc. Todos os direitos reservados, 1980 (Tradução do Padre Antonio Pereira de Figueiredo).

CARVALHO, Giselle de Castro de. A louca e o profeta: a presença do discurso religioso na loucura. Dissertação de mestrado em Letras. Niteroi: Universidade Federal Fluminense, 2004.

CASTRO, Selma. O discurso profético: ressacralização do espaço social. In: ORLANDI, Eni (org.). Palavra, Fé, Poder. Campinas: Pontes, 1987.

DIAS, Romualdo. De Deus ao seu povo. In: ORLANDI, Eni (org.). Palavra, Fé, Poder. Campinas: Pontes, 1987.

DICIONÁRIO Aurélio Século XXI, Aurélio Eletrônico (AE) Versão 3.0. Aurélio Buarque de Holanda Ferreira. Rio de Janeiro: Nova Fronteira, 2000.

FREUD, Sigmund. O futuro de uma ilusão (1927) In: Edição Standard Brasileira das Obras Psicológicas Completas de Sigmund Freud. Volume XXI. Rio de Janeiro: Imago Editora, 1974. 
GUELMAN, Leonardo. Brasil: Tempo de Gentileza. Niterói: EdUFF, 2000.

INDURSKY, Freda. A análise do discurso e sua inserção no campo das ciências da linguagem. In: Cadernos do $I L, \mathrm{n}$. 20, Universidade do Rio Grande do Sul, Instituto de Letras, Dezembro, 1998

KAPLAN, Harold. Compêndio de Psiquiatria: ciências do comportamento e psiquiatria clínica. 7 ed. Porto Alegre, RS: Artes Médicas, 1997 (capítulo 13 - Esquizofrenia).

MARIANI, Bethânia. O PCB e a imprensa. Rio de Janeiro: Revan, 1998.

NARLOCH, Leandro. O profeta do Deus único. In: Revista das Religiões. O Mundo da Fé, São Paulo, p. 16-21, ago. 2003.

NOVAES, Mariluci. Os dizeres nas esquizofrenias: uma cartola sem fundo. São Paulo: Editora Escuta, 1996.

NOVAES, Mariluci. Uma profecia, um delírio, uma teoria. In: Caderno de Letras 23, Universidade Federal Fluminense, Rio de Janeiro, 2002.

NOVAES, Mariluci. Os atos de fala nas psicoses: efeitos perlocucionários na interação entre médico e paciente. Trabalho apresentado no I Seminário da Pós-Graduação da Universidade Federal Fluminense, Niterói, 1997.

NOVAES, Mariluci. A contingência das metáforas. Trabalho apresentado no II Congresso Nacional da Associação Brasileira de Lingüística, ABRALIN, 1999.

ORLANDI, Eni. O discurso religioso. A linguagem $e$ o seu funcionamento. 2. ed. Campinas: Pontes, 1987.

ORLANDI, Eni. Interpretação: autoria, leitura e efeitos do trabalho simbólico. Petrópolis: Vozes, 1996.

ORLANDI, Eni. Análise do discurso: princípios e procedimentos. 3. ed. Campinas: Pontes, 2001

PÊCHEUX, Michel. Análise automática do discurso (1969). In: GADET, Françoise \& HAK, Tony. Por uma análise automática do discurso: Uma introdução à obra de Michel Pêcheux. 3. ed. Campinas: Pontes, 1997. 
PÊCHEUX, Michel. Semântica e discurso: uma crítica à afirmação do óbvio. 3. ed. Campinas: Editora da UNICAMP, 1997a.

PÊCHEUX, Michel.O discurso: estrutura ou acontecimento. 2. ed. Campinas: Pontes, 1997b.

PÊCHEUX, Michel \& FUCHS, Catherine. A propósito da Análise Automática do Discurso: atualização e perspectivas (1975) In: GADET, Françoise \& HAK, Tony. Por uma análise automática do discurso: Uma introdução à obra de Michel Pêcheux. 3. ed. Campinas: Pontes, 1997 